\title{
Congenital hypothyroidism detected by neonatal screening: relationship between biochemical severity and early clinical features
}

\author{
D B Grant, I Smith, P W Fuggle, S Tokar, J Chapple
}

\begin{abstract}
The relationships between biochemical severity of hypothyroidism (as judged by plasma thyroxine) and the clinical and radiographic findings at diagnosis were evaluated in 449 infants born in 1982-4 with congenital hypothyroidism identified by neonatal screening. Details of pregnancy, delivery, and the neonatal period were also examined and compared with the findings in a normal population of 36727 infants born in 1988. Infants with plasma thyroxine values of $30 \mathrm{nmol} / \mathrm{l}$ or less had a significantly higher incidence of prolonged jaundice, feeding difficulties, lethargy, umbilical hernia and macroglossia, showed more severe delay of bone maturation on a knee radiograph, and had a higher proportion of thyroid agenesis on isotope scan. In contrast, an ectopic or hypoplastic gland was more common in infants with plasma thyroxine values above $30 \mathrm{nmol} / \mathrm{l}$. Prevalence of illness in pregnancy and mode of delivery was not related to severity of hypothyroidism and were similar to figures for the normal population. Induction of labour, gestation over 40 weeks, and birth weight above $3500 \mathrm{~g}$ were significantly more common in the hypothyroid infants. Perinatal illness and congenital malformations were more common in the infants with low plasma thyroxine values at diagnosis.
\end{abstract}

Screening for congenital hypothyroidism started in the UK on a pilot basis in 1978; by mid-1982, after a recommendation by the Department of Health, ${ }^{1}$ routine screening had been introduced throughout the country. The Medical Research Council (MRC) Register of Children with Congenital Hypothyroidism was set up to collect detailed information on the outcome in children born with congenital hypothyroidism during 1982-4. Information on incidence, deaths, congenital malformations, and ethnic background has already been published. ${ }^{2}$

It has now become clear that there is considerable variation in the biochemical severity of hypothyroidism in children detected by screening $^{34}$ and that this variation is closely related to the type of thyroid disorder which is present. In general, agenesis of the thyroid is associated with severe hypothyroidism, while ectopia, hypoplasia, or inherited defects of thyroid hormone synthesis are often associated with a less severe biochemical disturbance. ${ }^{5-7}$ The present paper examines the relationship between biochemical severity (as judged by plasma thyroid hormone concentrations at diagnosis) and clinical features at diagnosis, early radio- logical findings (radiograph of the knee and isotope scan of the neck), pregnancy and perinatal events, and family history of thyroid disorder.

\section{Subjects and methods}

SUBJECTS

At the beginning of 1990 the register held the names of 472 children born between 1982 and 1984 who had been diagnosed by neonatal screening. This number includes 14 children who have since died and 15 who have been lost to follow up because of emigration or other change of address. Excluded from the present study were 23 children (including one who died) in whom plasma thyroid hormone concentrations had not been measured before treatment, leaving 449 children (139 boys and 310 girls).

\section{DATA COLLECTION AND STATISTICAL ANALYSES}

The paediatricians responsible for each child's clinical management were asked to provide details concerning pregnancy and birth, diagnosis, initiation of treatment, physical health, and family background. This information was recorded using a standard proforma which included a checklist of symptoms at the time of first clinical assessment (usually after a positive screening report) and requested the results of diagnostic tests, and of a radiograph of the knee and isotope scan of the neck (if performed).

Thyroid hormone concentrations at diagnosis had been measured either as total thyroxine $\left(\mathrm{T}_{4}\right)$ $(n=372)$, free thyroxine $\left(F_{4}\right)(n=75)$ or triiodothyronine $\left(T_{3}\right)(n=2)$. Before the start of treatment, 68 blood specimens were obtained from 58 children, each specimen was analysed for total thyroxine and free thyroxine, and from this analysis an equation was formulated:

$$
\log \mathrm{T}_{4}=2 \cdot 219+0 \cdot 9573 \times \log \mathrm{FT}_{4}
$$

Using this equation (S Tillotson, et al, personal communication), 55 definitive results for plasma free thyroxine were converted to total thyroxine values. The distribution of initial thyroxine values for 420 children are shown in the figure.

To examine the relationship between severity of hypothyroidism and other clinical variables it was decided to divide the children into two groups, group I with thyroxine values of $\mathbf{3 0}$ $\mathrm{nmol} / \mathrm{l}$ or less and group II with values greater than $30 \mathrm{nmol} / \mathrm{l}$. The value of $30 \mathrm{nmol} / \mathrm{l}$ was chosen as it divided the subjects into two roughly equal groups. A further seven children 


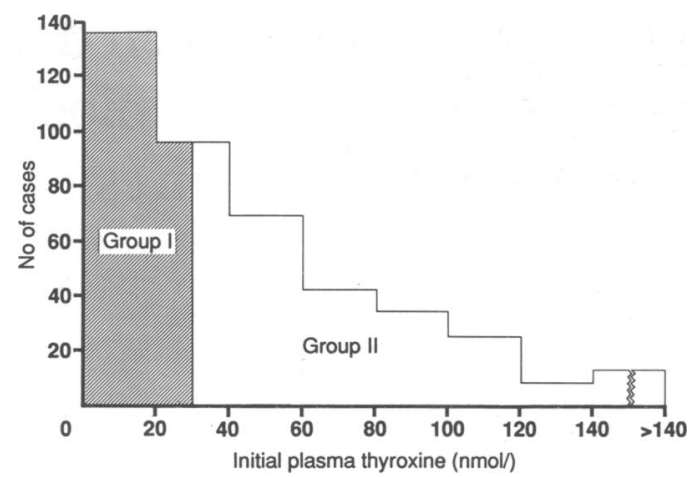

Distribution of initial plasma thyroxine values in 420 of the 449 children with congenital hypothyroidism detected by screening. The number of cases with low thyroxine concentrations is underestimated in the figure as 27 subjects were not included because the initial result was reported as 'less than 25 nmol/l' or 'less than 30 nmolll', or the free thyroxine as 'less than $2 \cdot 5 \mathrm{nmol} / \mathrm{l}$ ', and in two subjects plasma triiodothyronine concentrations were 0.5 and $0.7 \mathrm{nmol} / \mathrm{l}$.

with thyroxine results reported as 'less than 25 $\mathrm{nmol} / \mathrm{l}$ ' or 'less than $30 \mathrm{nmol} / \mathrm{l}$ ' and 20 with free thyroxine values reported as 'less than 2.5 nmol/l' were ascribed to group I, with two who had plasma triiodothyronine values of 0.5 and $0.7 \mathrm{nmol} / 1$, bringing group I to 215 cases and group II 234 cases.

The relationships between biochemical severity and other factors were explored in a series of tables. As not all of the subjects had a complete range of observations the tables are based on different combinations of subjects. Data on initial symptoms are available for 447 subjects, radiographs of the knee and isotope scans of the neck were carried out in 260 and 179 subjects respectively. Details of antenatal

Table 1 Prevalence of individual symptoms of hypothyroidism at the time of diagnosis. Results are number (\%)

\begin{tabular}{lcc}
\hline & $\begin{array}{c}\text { Group I } \\
(n=215)\end{array}$ & $\begin{array}{l}\text { Group II } \\
(n=232)\end{array}$ \\
\hline Features listed in questionnaire: & $128(59)$ & $77(33)^{* *}$ \\
Prolonged jaundice & $75(35)$ & $36(16)^{* *}$ \\
Feeding difficulty & $73(34)$ & $32(14)^{* *}$ \\
Lethargy & $68(32)$ & $42(18)^{*}$ \\
Umbilical hernia & $53(25)$ & $28(12)^{*}$ \\
Macroglossia & $38(18)$ & $24(10)$ \\
Constipation & $39(18)$ & $24(10)$ \\
Cold or mottled skin & $6(3)$ & $7(3)$ \\
Hypothermia & $34(16)$ & $78(33)^{* *}$ \\
No symptoms & $16(7)$ & $15(6)$ \\
Other clinical features reported: & $88(3)$ \\
Abnormal cry & $10(5)$ & $6(2)$ \\
Oedema & $12(6)$ & $7(3)$ \\
Hypothyroid appearance & $6(3)$ & 7 \\
Hypotonia &
\end{tabular}

Group I and group II had initial plasma thyroxine concentrations

$\leqslant 30 \mathrm{nmol} / \mathrm{l}$ or $>30 \mathrm{nmol} / \mathrm{l}$ respectively.
Significance of difference between groups: ${ }^{* *} \mathrm{p}<0.001,{ }^{*} \mathrm{p}<0.01$.

Table 2 Radiographic findings in the knee of 260 children with congenital hypothyroidism. Results are number (\%)

\begin{tabular}{llll}
\hline $\begin{array}{l}\text { Radiographic } \\
\text { findings }\end{array}$ & $\begin{array}{l}\text { Group I } \\
(n=131)\end{array}$ & $\begin{array}{l}\text { Group II } \\
(n=129)\end{array}$ & $\begin{array}{l}\text { Total } \\
(n=260)\end{array}$ \\
\hline Both epiphyses visible & $35(27)$ & $72(56)$ & $107(41)$ \\
Femoral epiphysis alone visible & $25(19)$ & $38(29)$ & $63(24)$ \\
Neither epiphysis visible & $71(54)$ & $19(15)$ & $90(35)$
\end{tabular}

Neither epiphysis visible

Group I and group II had initial plasma thyroxine concentrations $\leqslant 30 \mathrm{nmol} / 1$ or $>30 \mathrm{nmol} / \mathrm{l}$

respectively.
Significance of difference between groups: $\chi^{2}=45.47 ; \mathrm{p}<0.001$ progress were available in 449 subjects, whether or not induction was undertaken in 393 , mode of delivery in 421 , gestation length in 430 , and birth weight in 418 .

Prenatal and perinatal findings were compared with those in an unselected population of 36727 infants born in the north west Thames region in $1988 .{ }^{8}$

Where appropriate, differences between groups I and II, and between the overall group of children with congenital hypothyroidism and the normal population, were assessed using $\chi^{2}$ tests, taking a probability of less than 0.01 to indicate statistical significance.

\section{Results}

SYMPTOMS OF HYPOTHYROIDISM

The prevalence of symptoms (table 1), as defined by the checklist sent to paediatricians, was consistently greater in group I than in group II although the differences were only significant for the five most common symptoms. Jaundice for more than three weeks was the most commonly reported symptom, followed by feeding difficulty, lethargy, umbilical hernia, macroglossia, constipation, cold or mottled skin, and hypothermia. In group I $16 \%$ of the children had no symptoms compared with $33 \%$ in group II, whereas $13 \%$ of children in group I showed five or more symptoms compared with less than $2 \%$ in group II.

In 38 infants (25 group I; 13 group II) who had been suspected of having congenital hypothyroidism on clinical grounds before the screening result was known there was a significantly increased incidence of persistent jaundice (74\%) and feeding difficulties (58\%). Lethargy (37\%), macroglossia (24\%), umbilical hernia $(21 \%)$, constipation $(13 \%)$, or a cold mottled skin (13\%) were no more common than in the group as a whole.

BONE AGE AND THYROID SCAN

In 260 children who underwent radiography of one knee at diagnosis (table 2), both epiphyses were absent in $54 \%$ of group I compared with $15 \%$ in group II. By contrast, both epiphyses were visible in $56 \%$ of group II, compared with only $27 \%$ in group I, a highly significant difference.

Only 179 infants had an isotope scan (table 3) and of these $40 \%$ showed an absent thyroid gland. However, in group I the proportion was $73 \%$ compared with only $12 \%$ in group II, whereas $61 \%$ of group II had an ectopic gland compared with only $15 \%$ in group I. A normally sited gland (indicating a probable defect of thyroid hormone synthesis) was present with approximately equal frequency $(12 \%$ and $17 \%)$ in both groups of children. Hypoplastic or hemithyroid glands were reported in 10 infants all of whom had relatively mild hypothyroidism.

\section{PREGNANCY AND DELIVERY}

Sixty nine out of 447 mothers (15\%) were reported as having some complication or illness during pregnancy (table 4), a prevalence very 
similar to that in the general population of the north west Thames region; $9 \%$ of mothers had hypertension or toxaemia, and $2 \%$ insulin dependent or gestational diabetes mellitus; $4 \%$ had a range of different illnesses. Some form of medication (other than iron and vitamin preparations) during pregnancy was taken by $15 \%$, the most common being antibiotics $(5 \%)$, antiemetics $(3 \%)$, antihistamines $(2 \%)$, or sedatives $(1 \%) ; 19 \%$ reported smoking more than five cigarettes daily and 3\% drank alcohol regularly while pregnant. There were no differences between groups I and II.

Mean maternal age at delivery was $27 \cdot 1$ years $(n=341)$, compared with $28 \cdot 0$ years in the general population; mean paternal age was 30.3 years $(n=286)$. The mode of delivery was very similar in groups I and II and in the general population. However, labour was induced in $53 \%$ of group I and $35 \%$ of group II, compared with $15 \%$ of the general population, a trend which is highly significant.

\section{PERINATAL HISTORY}

Overall, $44 \%$ of the hypothyroid children had birth weights above $3500 \mathrm{~g}$ as compared with $36 \%$ in the general population, a highly significant difference. However, there was no significant difference in birth weight distribution between group I and group II.

Problems at or after birth were reported in 25 hypothyroid infants (table 5), 16 in group I (7\%) and nine in group II (4\%). In 11 infants illness was associated with prematurity and in nine of

Table 3 Thyroid scan findings in the 179 cases of congenital hypothyroidism. Results are number $(\%)$

\begin{tabular}{llll}
\hline $\begin{array}{l}\text { Thyroid } \\
\text { scan result }\end{array}$ & $\begin{array}{l}\text { Group I } \\
(n=84)\end{array}$ & $\begin{array}{l}\text { Group II } \\
(n=95)\end{array}$ & $\begin{array}{l}\text { Total } \\
(n=179)\end{array}$ \\
\hline Absent thyroid & $61(73)$ & $11(12)$ & $72(40)$ \\
Normally sited gland & $10(12)$ & $16(17)$ & $26(15)$ \\
Ectopic gland & $13(15)$ & $58(61)$ & $71(40)$ \\
Hypoplastic gland or hemithyroid & 0 & $10(11)$ & $10(6)$ \\
\hline
\end{tabular}

Group I and group II had initial plasma thyroxine concentrations $\leqslant 30 \mathrm{nmol} / 1$ or $>30 \mathrm{nmol} / \mathrm{l}$ respectively.

Significance of difference between groups: $\chi^{2}=72 \cdot 31 ; p<0.001$.

Table 4 Pregnancy and perinatal data in 449 children with congenital hypothyroidism compared with the normal population in the region. Results are number (\%)

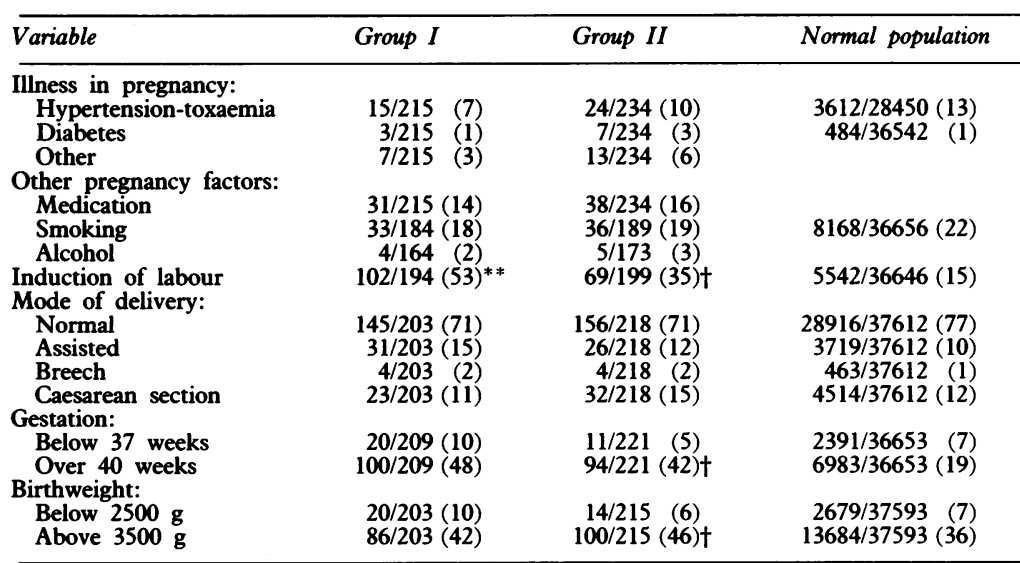

Group I and group II had initial plasma thyroxine concentrations $\leqslant 30 \mathrm{nmol} / 1$ or $>30 \mathrm{nmol} / 1$ respectively.

Significance of difference between groups: ${ }^{* *} \mathrm{p}<0.001$ and between all hypothyroid subjects and normal population: $t p<0 \cdot 001$.
normificance
Table 5 Perinatal illness, congenital malformations, and deaths in 449 children with congenital hypothyroidism

\begin{tabular}{lll}
\hline & $\begin{array}{l}\text { Group I } \\
(n=215)\end{array}$ & $\begin{array}{l}\text { Group II } \\
(n=234)\end{array}$ \\
\hline Perinatal illness & $16^{*}$ & 9 \\
Birth asphyxia & 3 & 2 \\
Respiratory distress syndrome & 1 & 4 \\
Pneumonia/aspiration & 4 & 2 \\
Septicaemia/necrotising enterocolitis & 6 & 0 \\
Hypoglycaemia & 1 & 1 \\
$\quad$ Hypocalcaemia & 1 & 0 \\
Congenital malformations & $26^{*}$ & 9 \\
Deaths & 10 & 3
\end{tabular}

Group I and group II had initial plasma thyroxine concentrations $\leqslant 30 \mathrm{nmol} / 1$ or $>30 \mathrm{nmol} / 1$ respectively. Significance of difference between groups: ${ }^{*} \mathrm{p}<0.01$.

them the birth weight was less than $2500 \mathrm{~g}$. Thirty two children were recorded as having congenital anomalies (other than of the thyroid gland) when first assessed. Follow up revealed anomalies in another three patients, giving an overall incidence of $8 \%$. Twenty six of these infants were in group I and nine were in group II $(p<0 \cdot 01)$. Ten children in group I died before the age of 2 years, compared with three in group II.

\section{FAMILY HISTORY OF THYROID DISEASE}

By the end of 1989,15 children (3\%) (including two pairs of twins) had a sibling with congenital hypothyroidism. Of the four who had thyroid scans, three (including one pair of twins) had a normal or enlarged gland, indicating probable dyshormonogenesis. As thyroid scans were carried out on less than half the patients only 153 children with dysgenesis of the thyroid have been identified. These children have a total of 214 siblings, only one of whom has congenital hypothyroidism. Two girls with congenital hypothyroidism are maternal cousins and an isotope scan in one of them showed no evidence of thyroid tissue.

Thyroid disease was reported in 13 mothers (3\%); five had goitres, three thyroglossal cysts, two hypothyroidism, and three hyperthyroidism.

\section{Discussion}

One of the most striking features of congenital hypothyroidism to have emerged since the introduction of neonatal screening is a very wide range in biochemical severity at the time of diagnosis. ${ }^{2} 3$ Screening has allowed early identification of children with mild as well as severe forms of the disorder and this probably accounts for the apparent increase in the incidence of congenital hypothyroidism noted when screening first began, along with a considerable decline in the frequency of juvenile hypothyroidism' presenting during later childhood. In the present study 46 subjects $(10 \%)$ had normal plasma thyroxine values at the time of diagnosis, and while it remains possible that a few of these children may still prove to have normal thyroid function, most $(89 \%)$ have been shown to have raised values of thyroid stimulating hormone either on treatment or after its temporary withdrawal. 
In the present study there was a close relationship between the biochemical severity of hypothyroidism and clinical symptoms. Infants with plasma thyroxine concentrations below $\mathbf{3 0}$ $\mathrm{nmol} / \mathrm{l}$ were much more likely to show prolonged jaundice, feeding difficulties, lethargy, umbilical hernia, and macroglossia than those with a less appreciable reduction in thyroxine values. Others have shown that such symptoms can also be used to differentiate hypothyroid infants from those with false positive screening results. In an important study from Finland, Virtanen compared the clinical findings at the age of 6 days in 95 newborn infants with hypothyroidism and 450 infants with false positive screening test results. ${ }^{9}$ Jaundice, macroglossia, and hypothyroid appearance, abdominal distension, umbilical hernia, and cold skin were very much more common in the hypothyroid group, as were prolonged gestation, high birth weight, an above average head circumference, and a good Apgar score. In a smaller study, Rochiccioli et al found that the presence of macroglossia, umbilical hernia, hypothyroid appearance, cold mottled skin, and a wide posterior fontanelle could be used to separate hypothyroid infants from those with false positive screening tests. ${ }^{5}$ Nevertheless, it should be noted that in the present study $16 \%$ of the infants with severe hypothyroidism were symptom free at the time of detection.

As has been reported previously, ${ }^{3-5}$ biochemical severity was closely related to bone age. There is also evidence suggesting that the degree of bone age retardation may be of prognostic value with respect to later intelligence. ${ }^{10-13}$

A relationship between thyroid scan results and the early biochemical findings is well recognised. ${ }^{5-7}$ In the present study, the thyroid scan findings were more closely related to severity of hypothyroidism than any other factors. Of those who were scanned, $40 \%$ showed agenesis of the gland and $85 \%$ of these had plasma thyroxine values of $30 \mathrm{nmol} / \mathrm{l}$ or less; $46 \%$ had an ectopic, hypoplastic, or hemithyroid and only $16 \%$ of these showed a comparable reduction in plasma thyroxine values, illustrating the close association between agenesis and severe biochemical disease. Estimates of the prevalence of agenesis of the thyroid in series from other countries have varied from $15 \%$ to $51 \%$ but some of this variation may be due to different sensitivities in the scanning technique. The scan results described above suggest a prevalence of thyroid hormone biosynthetic defects of $15 \%$ in the UK, similar to that found in France and Finland $(13 \%) .^{514}$ This is a little lower than reported from North America $(20-22 \%)^{4} 7$ and higher than in Switzerland $(6 \%) .15$

Although our study failed to identify any differences in maternal factors during pregnancy or in the mode of delivery between infants with congenital hypothyroidism and the general population, there was a striking increase in the frequency of induced labour and higher frequencies of postmaturity and infants with birth weights over $3500 \mathrm{~g}$. The increased prevalence of postmaturity is a well recognised feature of congenital hypothyroidism, ${ }^{416} 17$ although its significance with respect to the physiology of labour is still uncertain. A number of authors have also reported increased birth weight as a feature of congenital hypothyroidism. ${ }^{11} 1617$

As reported previously, ${ }^{218-20}$ congenital hypothyroidism is associated with an increased prevalence of other congenital anomalies, and almost $8 \%$ of the present sample had major malformations, compared with an expected frequency of $2-3 \%$. The data suggest that some teratogenic factor is operating during early pregnancy but our study failed to identify any such factor other than the hypothyroidism itself.

This paper forms a report for the steering committee for the Medical Research Council's register of children with congenital hypothyroidism (Chairman Professor J A Davis).

We thank all the paediatricians across the country who have responded to our questionnaires and provided the data which make up this report. The study was supported by a project grant from the Medical Research Council.

1 Department of Health and Social Security. Screening for early detection of congenital hypothyroidism. London: DHSS, 1981. (HN (81)20.)

2 Grant DB, Smith I. Survey of neonatal screening for primary hypothyroidism in England, Wales and Northern Ireland hypothyroidism in England, Wa

3 Hulse JA, Grant DB, Clayton BE, et al. Population screening for congenital hypothyroidism. BMF 1980;280:675-8.

4 LaFranchi SH, Hanna CE, Krinnz PL, Skeels MR, Miyahira RS, Sesser DE. Screening for congenital hypothyroidism with specimen collection at two time periods: results of the Northwest Region Screening Program. Pediatrics 1985;76: 734-40.

5 Rochiccioli P, Dutau G, Roge B, Petrus M, Augier D, Enjaume C. Le depistage neonatal de l'hypothyroidie en France. $\mathcal{F}$ Genet Hum 1981;29:13-22.

6 O'Connor MK, Freyne PJ, Cullen MJ. Low dose radioisotope scan and quantitative analysis in the diagnosis of congenital hypothyroidism. Arch Dis Child 1982;57:490-4.

7 New England Congenital Hypothyroidism Collaborative. Characteristics of infantile hypothyroidism discovered on neonatal screening. F Pediatr 1984;104:539_44.

8 Maresh M, Dawson AM, Beard RLO. Assessment of an on line perinatal data collection and information system. $\mathrm{Br} \mathcal{F}$ line perinatal data collection and in
Obstet Gynaecol 1989;93:1239-85.

9 Virtanen M. Manifestations of congenital hypothyroidism during the 1st week of life. Eur $\mathcal{F}$ Pediatr 1988;147:270-4.

10 Rochiccioli P, Dutau G, Despert F, Roge B, Sablayrolles B, Enjaume C. La surface des epiphyses du genou: index d'anciennete de l'hypothyroidie neonatale. Arch Fr Pediatr 1984;41:329-32.

11 Murphy G, Hulse JA, Jackson D, et al. Early treated hypothyroidism: development at 3 years. Arch Dis Child 1986;61:761-5.

12 Rovet J, Ehrlich R, Sorbara D. Intellectual outcome in children with fetal hypothyroidism. F Pediatr 1987;110: $700-4$.

13 Toublanc JE, Rives S, Acosta A, Chicaud J. Le developpement psychomoteur et intellectuel chez 52 enfants atteints d'hypothyroidie congenitale depistee à la naissance. Arch Fr Pediatr 1990;47:191-5.

14 Virtanen M, Santavouri P, Hirvonen E, Perheentupa J. Value of very early therapy in congenital hypothyroidism. Acta Paediatr Scand 1985; suppl 322:22.

15 Illig $\mathrm{R}$, Largo RH, Weber $M$, et al. Sixty children with congenital hypothyroidism detected by neonatal screening: mental development at 1,4 , and 7 years: a longitudinal study. Acta Endocrinol 1986;suppl 279:346-53.

16 Maenpaa J. Congenital hypothyroidism: aetiological and clinical aspects. Arch Dis Child 1972;47:914-23.

17 Letarte J, LaFranchi S. Clinical features of hypothyroidism. In: Dussault JH, Walker P, eds. Congenital hypothyroidism. (Basic and clinical endocrinology 2.) New York: Dekker, 1983:351-83

18 Goujard J, Safar A, Rolland A, Job JC. Epidemiologie des hypothyroides congenitales malformatives. Arch Fr Pediatr 1981;38:875-79.

19 Bamforth JS, Hughes I, Lazarus J, John R. Congenital anomalies associated with hypothyroidism. Arch Dis Child 1986;61:608-9.

20 Fernhoff PM, Brown AL, Elsas JL. Congenital hypothyroidism: increased risk of neonatal morbidity results in delayed treatment. Lancet 1987;ii:490-1. 